\title{
A novel lipoprotein lipase gene missense mutation in Chinese patients with severe hypertriglyceridemia and pancreatitis
}

Tan-Zhou Chen ${ }^{1 \dagger}$, Sai-Li Xie ${ }^{1 \dagger}$, Rong Jin $^{2}$ and Zhi-Ming Huang ${ }^{1 *}$

\begin{abstract}
Background: Alterations or mutations in the lipoprotein lipase (LPL) gene contribute to severe hypertriglyceridemia (HTG). This study reported on two patients in a Chinese family with LPL gene mutations and severe HTG and acute pancreatitis.

Methods: Two patients with other five family members were included in this study for DNA-sequences of hyperlipidemia-related genes (such as LPL, APOC2, APOA5, LMF1, and GPIHBP1) and 43 healthy individuals and 70 HTG subjects were included for the screening of LPL gene mutations.

Results: Both patients were found to have a compound heterozygote for a novel LPL gene mutation ( $L 279 \mathrm{~V})$ and a known mutation (A98T). Furthermore, one HTG subject out of 70 was found to carry this novel LPL L279V mutation.

Conclusions: The data from this study showed that compound heterozygote mutations of A98T and L279V inactivate lipoprotein lipase enzymatic activity and contribute to severe HTG and acute pancreatitis in two Chinese patients. Further study will investigate how these LPL gene mutations genetically inactivate the LPL enzyme.
\end{abstract}

Keywords: Lipoprotein lipase deficiency, LPL gene, Mutation, Hypertriglyceridemia, Pancreatitis

\section{Background}

Lipoprotein lipase (LPL) is a member of the lipase gene family, which includes lipases in the pancreas, liver, and endothelium and plays a critical role in metabolism of triglyceride (TG) by hydrolyzing TG-rich lipoprotein to free fatty acids using apolipoprotein C-II (apoC-II) as a cofactor. Alterations or mutations in the LPL gene could result in massive accumulation of chylomicrons and profound fasting hypertriglyceridemia (HTG) [1]. Patients with severe HTG (TG> $11.3 \mathrm{mmol} / \mathrm{l})$ usually suggest genetic reasons and show clinical features of recurrent attacks of pancreatitis, hepatosplenomegaly, lipemia retinalis and eruptive xanthomas. The primary severe HTG may be caused by gene mutations, including deficiency of LPL, apoC-II and apoA-V, correspondingly to mutations of LPL, APOC2, and APOA5 genes, respectively [2,3]. Recently, other two novel proteins were identified to be

\footnotetext{
* Correspondence: hzmwenzhou@163.com

${ }^{\dagger}$ Equal contributors

${ }^{1}$ The Department of Gastroenterology and Hepatology, The First Affiliated

Hospital of Wenzhou Medical University, Wenzhou, China

Full list of author information is available at the end of the article
}

essential for proper LPL function, i.e., lipase maturation factor1 (LMF1) and glycosylphosphatidylinositol-anchored high-density lipoprotein-binding protein 1 (GPIHBP1); thus, they are of importance for studying HTG $[4,5]$, although mutations of LPL gene are responsible for the most common form of primary severe HTG.

Human LPL gene is composed of 10 exons and spans approximately $30 \mathrm{~kb}$ on chromosome $8 \mathrm{p} 22$ encoding a protein with 448 amino acids [6]. LPL gene mutations include insertion, duplication, deletion, nonsense, frameshift, or missense mutations. Most LPL gene mutationscaused LPL deficiency are due to missense mutations, although other types of mutations have been previously reported [7]. To date, there are over a hundred LPL gene mutations reported in the literature to cause clinical hyperchylomicronemia syndrome in the Human Gene Mutation Database. In this study, we described a novel LPL gene missense mutation (L279V) in two Chinese patients with severe HTG and acute pancreatitis.

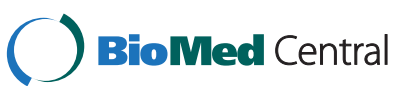

(c) 2014 Chen et al.; licensee BioMed Central Ltd. This is an Open Access article distributed under the terms of the Creative Commons Attribution License (http://creativecommons.org/licenses/by/2.0), which permits unrestricted use, distribution, and reproduction in any medium, provided the original work is properly credited. The Creative Commons Public Domain Dedication waiver (http://creativecommons.org/publicdomain/zero/1.0/) applies to the data made available in this article, unless otherwise stated. 


\section{Subjects and methods Subjects}

In the present study, a 28-year-old female Han Chinese with her first pregnancy during the third trimester was admitted to our emergency room and diagnosed with acute pancreatitis. Several days prior to this episode, lactescent levels were elevated in her serum however this was not noted. When admitted, blood tests revealed extremely high serum levels of HTG (TG $79 \mathrm{mmol} / \mathrm{l}$, while normal ranges are $0.0-1.7 \mathrm{mmol} / \mathrm{l})$. Following immediate cesarean section, she gave birth to a healthy baby girl and then was treated with dietary restriction and supportive treatment for 28 days, then discharged from the hospital.

Meanwhile, the 58-year-old mother was also admitted to our hospital with a diagnosis of acute pancreatitis. Including this hospitalization, she had two previous episodes of abdominal pain and was diagnosed with acute pancreatitis after intake of fatty food. The plasma levels of total triglyceride were 25.4 and $16.3 \mathrm{mmol} / \mathrm{l}$, respectively at these episodes. The proband' mother was married to her father at age 22 through a consanguineous marriage. Because these two patients presented with severe HTG and acute pancreatitis, they were strongly suggestive of an inherited condition.

Thus, we included not all but five of their family members, i.e., the father, two aunts, one uncle and one sister in our study. They all were shown to have mild hyperlipidemia but no history of diabetes mellitus, abdominal pain or pancreatitis. In addition, we also recruited an additional 43 healthy individuals and 70 unrelated HTG subjects as controls for this study.

This study was approved by the Ethics Committee of Wenzhou Medical University and signed informed consent was obtained from all subjects participated in this study.

\section{Measurement of plasma lipase and LPL mass and activity} Blood samples were collected into Na-EDTA tubes $15 \mathrm{~min}$ following an intravenous heparin (60 IU/kg body weight) injection in these patients and in 10 healthy controls, including 5 men and 5 women after an overnight fast. LPL enzyme activity in post-heparin treatment was measured as described previously [8]. LPL mass was measured using a sandwich-ELISA with a Human Lipoprotein Lipase ELISA Kit (Nanjing Jiancheng, Nanjing, China).

Plasma lipid concentrations were also measured using standardized enzymatic methods as described previously [9]. The serum was diluted with saline solution (1:5) before measurement of HDL-C due to the high TG concentration for the daughter.

PCR-amplification and DNA-Sequencing of candidate genes Genomic DNA was extracted from $2 \mathrm{ml}$ whole blood samples using a Gentra Puregene Blood kit according to the manufacturers' instructions (Qiagen, Dusseldorf,
Germany). All coding regions and the intron-exon boundaries of LPL (NM_000237), APOC2 (NM_000483), APOA5 (NM_052968), LMF1 (NM_022773), and GPIHBP1 (NM_178172) genes were PCR-amplified and bidirectionally DNA-sequenced using the Sanger method based on dideoxy chain-termination technology, as described previously $[10,11]$.

\section{Screening for LPL gene mutations}

The screening of the novel LPL variant L279V and the known variant A98T were performed in 43 healthy individuals and 70 HTG subjects using an i-plexGOLD genotyping assay of the MassARRAY mass-spectrometry system, following the protocol recommended by the manufacturer (Sequenom, Santiago, USA).

\section{Species examination}

We examined evolutionary conservation of the L279 amino acid residue across various species from chimpanzee (a close evolutionary relative) to wild goose and zebra fish (both distant evolutionary counterparts).

\section{Results}

\section{Genetic and biochemical features of the patients}

Pedigree of the probands is shown in Figure 1. Mutational analyses of the LPL, APOC2, APOA5, LMF1, and GPIHBP1 genes showed that both patients had the same compound heterozygote of the LPL gene for a novel missense mutation (L279V) and a known missense mutation (A98T). One unrelated HTG patient was also found to be heterozygote of the p.(L279V) variant. The novel missense mutation L279V (p.L279V, rs371282890) at exon 6 is a CTG $\rightarrow$ GTG change in codon 279 of the LPL gene, leading to $\mathrm{L} \rightarrow \mathrm{V}$ amino acid substitution in the LPL protein (Figure 2). The known missense mutation of LPL A98T (p.A98T, rs145657341) is a GCC $\rightarrow$ ACC change in codon 98 of the LPL gene, leading to an $\mathrm{A} \rightarrow \mathrm{T}$ amino acid substitution (Figure 3 ). The father (I3) was found to be a carrier of L279V, while the uncle (I2), one aunt (I5) and the elder sister (II3) were carriers of A98T. I2, I5, I6 also have S447X mutations. There were no mutations found in APOC2, APOA5, GPIHBP1 or LMF1.

LPL mutations and biochemical features of these two patients and their family members are shown in Table 1. However, in cross species comparison, we found that L279 residue is very conserved across the species (Figure 4).

\section{Screening for LPL gene mutations in HTG subjects}

Among the 70 unrelated HTG subjects, we found one HTG subject who carried the L279V mutation. This patient had an episode of acute pancreatitis and the TG levels were $15.3 \mathrm{mmol} / \mathrm{l}$. Thus, we further analyzed and DNA-sequenced his genomic DNA for LPL, APOC2, APOA5, LMF1 and GPIHBP1 genes. The data showed 


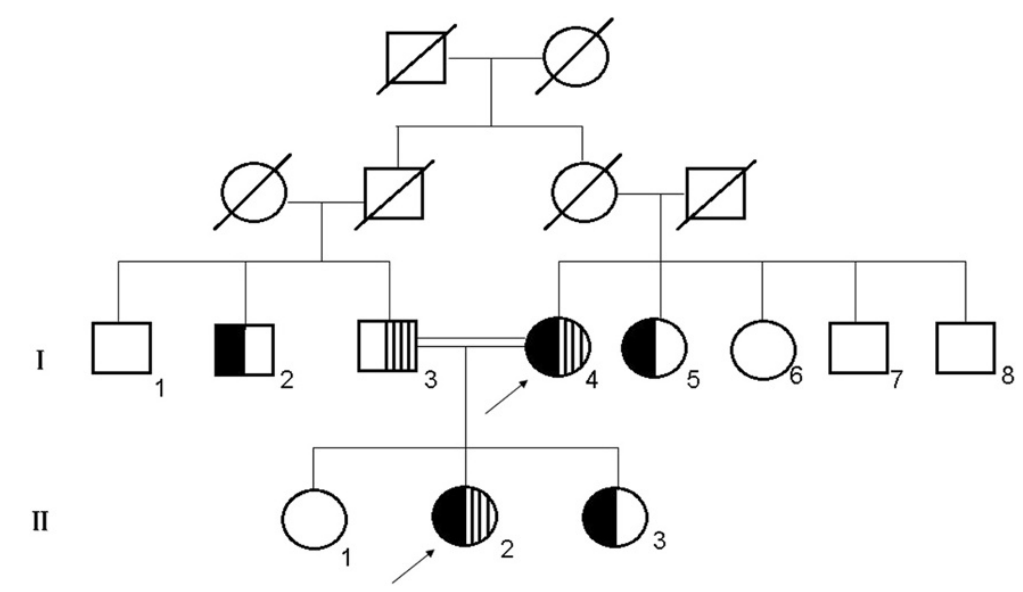

Figure 1 Pedigree of the patient's family. Black symbols represent the presence of a A98T mutation. Shaded symbols represent the presence of a L279V mutation. The arrow indicates probands. Parental consanguinity is indicated by a double line. | 1, | 7, I 8 and ||1 were not a part of the study.

that a missense mutation of GPIHBP1 gene (p.C14F, rs11538389) with heterozygosity of the gene. However, both A98T and L279V mutations were not found in any healthy individuals and other HTG subjects.

Detection of post-heparin LPL activity and mass levels in patients and controls

We then detected post-heparin LPL activity and mass levels in patients and controls and found that compared

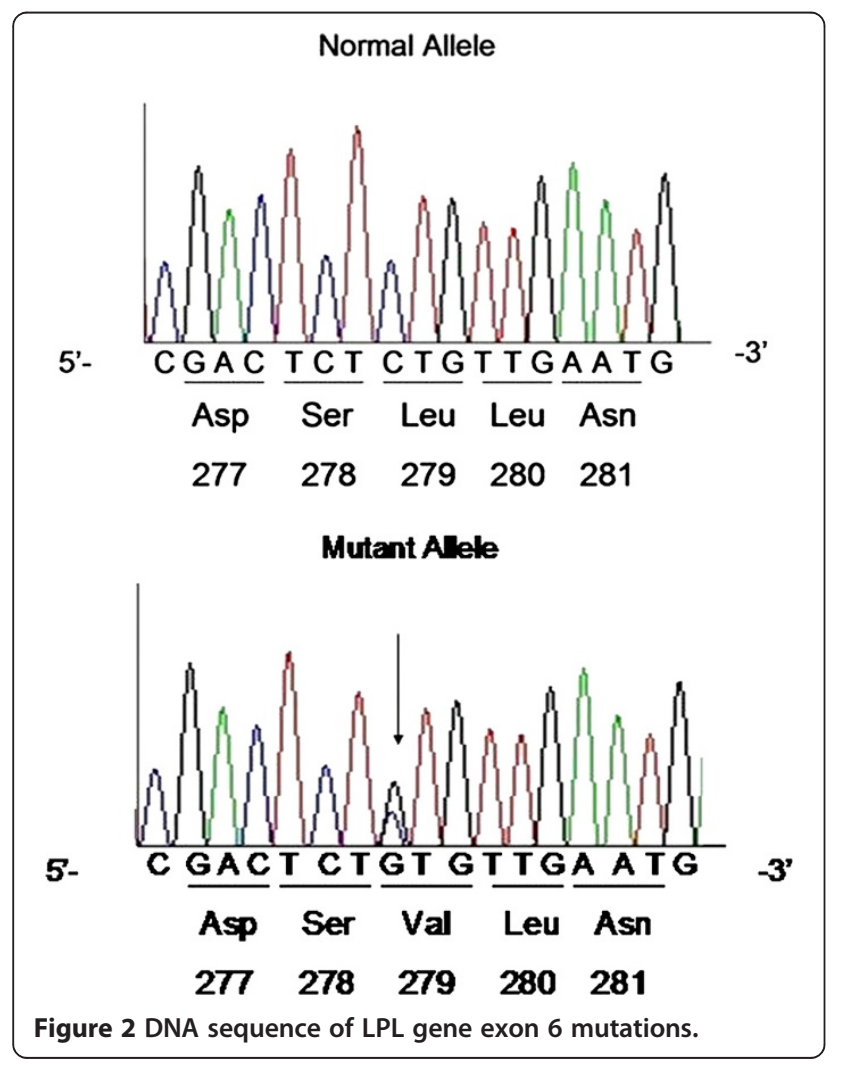

to normal controls, the post-heparin LPL activity of the proband and her mother were reduced by $55.4 \%$ and $32.1 \%$, respectively, although their plasma LPL mass was close to the normal controls (data not shown).

\section{Discussion}

In the current study, we showed two-related patients who manifested massive HTG and acute pancreatitis with a low LPL post-heparin activity. Both probands present the same LPL genotype with a compound heterozygote for a known missense mutation A98T in exon3 and a

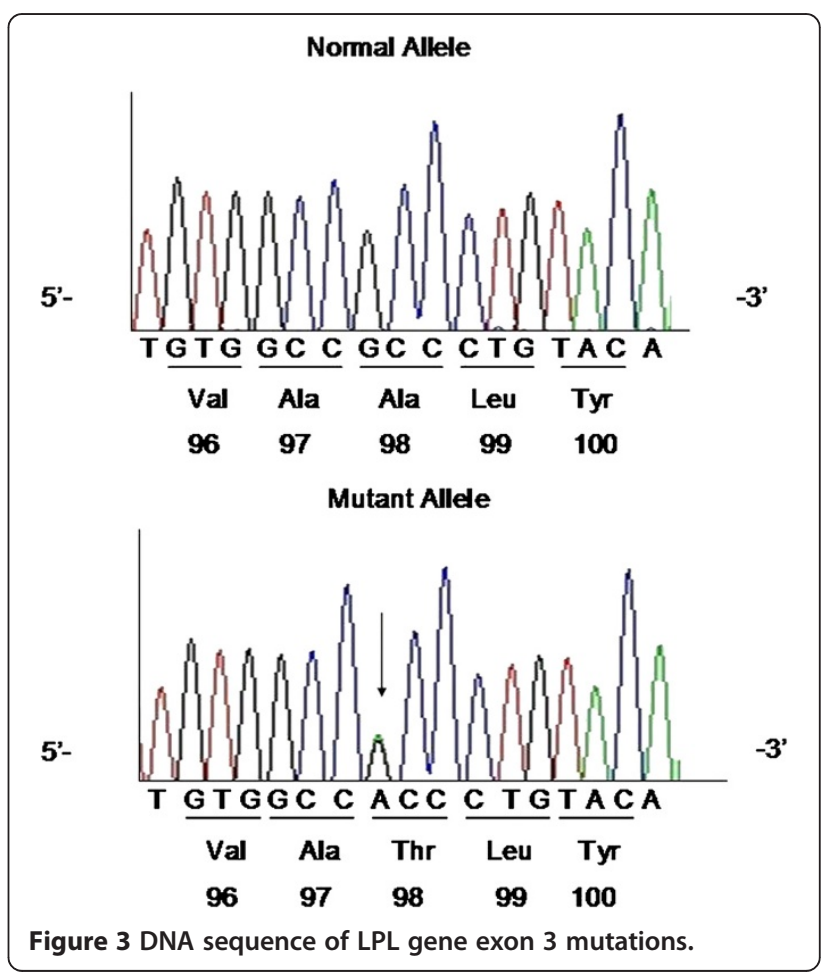


Table 1 LPL mutations and biochemical features of the 2 probands and their family members

\begin{tabular}{|c|c|c|c|c|c|c|c|c|}
\hline \multirow[t]{2}{*}{ Subject } & \multirow[t]{2}{*}{ Status } & \multirow[t]{2}{*}{ Genotype } & \multirow[t]{2}{*}{ Sex/age } & \multirow{2}{*}{$\begin{array}{c}\text { BMI } \\
\left(\mathrm{kg} / \mathrm{m}^{2}\right)\end{array}$} & \multicolumn{4}{|c|}{ Plasma lipid levels $\left(\mathrm{mmolL}^{-1}\right)$} \\
\hline & & & & & TC & TG & HDL-C & LDL-C \\
\hline 12 & Uncle & A98T/S447X & M/69 & 24.2 & 5.36 & 4.53 & 1.02 & 1.78 \\
\hline 13 & Father & L279V & M/63 & 23.5 & 5.13 & 2.03 & 1.21 & 1.53 \\
\hline 14 & Mother(proband1) & L279V/A98T & $\mathrm{F} / 58$ & 19.2 & 7.99 & 16.33 & 0.54 & 1.28 \\
\hline 15 & Niece & A98T/S447X & $F / 69$ & 21.6 & 5.07 & 5.77 & 1.12 & 1.67 \\
\hline 16 & Niece & S447X & $F / 66$ & 20.1 & 5.72 & 5.45 & 1.36 & 2.06 \\
\hline 112 & Daughter(proband2) & L279V/A98T & $F / 28$ & 19.6 & 38.4 & 79.0 & 0.61 & 2.48 \\
\hline 113 & Daughter & A98T & $F / 32$ & 19.8 & 5.32 & 5.13 & 1.25 & 1.82 \\
\hline
\end{tabular}

BMI, body mass index; TC, total cholesterol; TG, total triglyceride; HDL-C, high-density lipoprotein cholesterol; LDL-C, low-density lipoprotein cholesterol.

novel missense mutation L279V in exon 6 of LPL gene. Moreover, the novel mutation L279V was also found in one of 70 HTG individuals.

To date, the majority disease-causing LPL gene mutations occurs at exon 4, 5 and 6 residues (117-312), which constitute a large N-terminal domain (residues 1-312) of the enzyme and this region is the most conserved and important for LPL catalytic functions [12]. Exon 6 (residues 232-313) encodes two structurally relevant disulfide bridges (Cys278-Cys283 and Cys264-Cys275) for the binding of heparin [13]. The novel mutation L279V constitutes one of these two disulfide bridges (Cys278-Cys283), which is important for catalytic function of heparin binding. Both patients had low post-heparin LPL activity but normal levels of mass, further demonstrating this possibility.

Furthermore, we also assessed the L279V mutation disease-causing potential by comparing it across various species. We found that the L279 site is indeed conserved throughout evolution from chimpanzee to zebra fish, suggesting that this residue may play a critical role in LPL function. In the current study, we found a total of

\begin{tabular}{|ll|}
\hline HERSI HLFIDS L LNEENPSKAYRCSS & Human \\
HERSI HLFIDS L LNEENPSKAYRCNS & Mouse \\
HERSI HLFIDS L LNEENPSKAYRCSS & Chimpanzee \\
HERSVHLFIDS L LNEENPSKAYRCNS & Sheep \\
HERSVHLFIDS L LNEENPSKAYRCNS & Cow \\
HERSI HLFIDS L L LNEENPSKAYRCSS & Monkey \\
HERSI HLFIDS L LNEENPAKAYRCNS & Pig \\
HERSI HLFIDS L LYEEKPSMAYRCNT & Duck \\
HERSI HLFIDS L LYEEKPSMAYRCNT & Chicken \\
HERSI HLFIDS L LNEENPSKAYRCNS & Cat \\
HERSI HLFIDS L LNEENPSKAYRCSS & Baboon \\
HERSI HLFIDS L VNQDHESMAFRCSS & Zebrafish \\
HERSI HLFIDS L LYEEKPSMAYRCNT & Wild goose \\
HERSI HLFIDS L LNEENPSKAYRCNS & Dog \\
HERSI HLFIDS L LNEENPSKAYRCNS & Horse \\
Figure 4 Comparison of evolutionary conservation of the L279 \\
amino acid residue in various species.
\end{tabular}

four carriers of L279V mutation including the two patients and one family member, and an unrelated HTG individual, all of whom were heterozygotes for this missense mutation. This novel LPL mutation (L279V) was submitted to NCBI and the Submitter SNP accession number is ss\#550039488. In addition, the known LPL gene mutation A98T has been described previously with lipoprotein lipase deficiency in the clinic [14]. To date, there were three family members found to carry this mutation, one with a single mutation and others with compound heterozygous for another nonsense mutation S447X of LPL.

Patients with two defective LPL alleles will have no or markedly reduced LPL activity, thus, homozygous or compounds of heterozygous mutations lead to severe HTG while one defective LPL allele may have normal to moderately increased blood levels of fasting triglyceride [15-17]. In this study, the mother and daughter had the same LPL genotype with compound heterozygous mutations of A98T and L279V; thus, both manifested massive HTG and acute pancreatitis. In contrast, the family members who carried a single mutation either A98T or L279V, only presented mild HTG and had no history of acute pancreatitis. Moreover, another unrelated HTG individual, who had the compound heterozygote L279V and a known GPIHBP1 mutation, suffered from a severe HTG and acute pancreatitis.

In the current study, we found that two family members had compound LPL gene A98T and S447X mutations, but they also had mild elevated blood TG levels. The reason for this is unclear, but may be because of the special mutation S447X. In a previous study, LPL S447X mutation was shown to have a naturally occurring gain-function [18]. This LPL mutation S447X is the only mutation that has a protective effect against the development of HTG and coronary heart disease by decreasing plasma TG levels in the clinic and increasing HDL production [19]. Thus, gene therapy using the S447X variant has shown therapeutic promise in the study of LPL deficiency [20]. 


\section{Competing interests}

There are no potential competing interests to declare.

\section{Authors' contribution}

Z-MH planned the study protocol, took care about the patients and coordinated the research, T-ZC took part in the data analysis and drafted the manuscript acquisition of data, S-LX conceived of the study, participated in its coordination, revised it critically and prepared the final version of the manuscript, RJ participated in the study coordination and took part in the data analysis. All authors read and approved the final manuscript.

\section{Acknowledgements}

The present work was supported by research grants, Fund for Nature of Wenzhou (Y20130050) to Dr. Tan-Zhou Chen from Wenzhou Science \& Technology Bureau, China.

\section{Author details}

${ }^{1}$ The Department of Gastroenterology and Hepatology, The First Affiliated Hospital of Wenzhou Medical University, Wenzhou, China. ${ }^{2}$ Department of Epidemiology, The First Affiliated Hospital of Wenzhou Medical University, Wenzhou, China.

Received: 21 January 2014 Accepted: 11 March 2014

Published: 19 March 2014

\section{References}

1. Fisher RM, Humphries SE, Talmud PJ: Common variation in the lipoprotein lipase gene: effects on plasma lipids and risk of atherosclerosis. Atherosclerosis 1997, 135:145-59.

2. Pennacchio LA, Rubin EM: Apolipoprotein A5, a newly identified gene that affects plasma triglyceride levels in humans and mice. Arterioscler Thromb Vasc Biol 2003, 23:529-34.

3. Fojo SS, Brewer HB: Hypertriglyceridaemia due to genetic defects in lipoprotein lipase and apolipoprotein C-II. J Intern Med 1992, 231:669-677.

4. Peterfy M, Ben-Zee O, Mao HZ, Weissglas-Volkov D, Aouizerat BE, Pullinger CR Frost PH, Kane JP, Malloy MJ, Reue K, Pajukanta P, Doolittle MH: Mutations in LMF1 cause combined lipase deficiency and severe hypertriglyceridemia. Nat Genet 2007, 39:1483-7.

5. Olivecrona G, Ehrenborg E, Semb H, Makoveichuk E, Lindberg A, Hayden MR, Gin P, Davies BS, Weinstein MM, Fong LG, Beigneux AP, Young SG, Olivecrona T, Hernell O: Mutation of conserved cysteines in the Ly6 domain of GPIHBP1 in familial chylomicronemia. J Lipid Res 2010, 51:1535-45.

6. Wion KL, Kirchgessner TG, Lusis AJ, Schotz MC, Lawn RM: Human lipoprotein lipase complementary DNA sequence. Science 1987, 235:1638-41.

7. Rahalkar AR, Giffen F, Har B, Ho J, Morrison KM, Hill J, Wang J, Hegele RA, Joy T: Novel LPL mutations associated with lipoprotein lipase deficiency: two case reports and a literature review. Can J Physiol Pharmacol 2009, 87:151-160.

8. Nozaki S, Kubo M, Matsuzawa Y, Tarui S: Sensitive non-radioisotopic method for measuring lipoprotein lipase and hepatic triglyceride lipase in post-heparin plasma. Clin Chem 1984, 30:748-751.

9. Pasalic D, Jurcic Z, Stipancic G, Ferencak G, Leren TP, Djurovic S, StavljenicRukavina A: Missense mutation W86R in exon 3 of the lipoprotein lipase gene in a boy with chylomicronemia. Clin Chim Acta 2004, 343:179-184.

10. Surendran RP, Visser ME, Heemelaar S, Wang J, Peter J, Defesche JC, Kuivenhoven JA, Hosseini M, Peterfy M, Kastelein JJ, Johansen CT, Hegele RA, Stroes ES, Dallinga-Thie GM: Mutations in LPL, APOC2, APOA5, GPIHBP1 and LMF1 in patients with severe hypertriglyceridaemia. J Intern Med 2012, 272:185-196.

11. Coca-Prieto I, Kroupa O, Gonzalez-Santos P, Magne J, Olivecrona G, Ehrenborg E, Valdivielso P: Childhood-onset chylomicronaemia with reduced plasma lipoprotein lipase activity and mass: identification of a novel GPIHBP1 mutation. J Intern Med 2011, 270:224-228.

12. van Tilbeurgh H, Roussel A, Lalouel JM, Cambillau C: Lipoprotein lipase. Molecular model based on the pancreatic lipase x-ray structure: consequences for heparin binding and catalysis. J Biol Chem 1994, 269:4626-4633.

13. Renier G, Desfaits AC, Lambert A, Mikhail R: Role of oxidant injury on macrophage lipoprotein lipase (LPL) production and sensitivity to LPL. J Lipid Res 1996, 37:799-809.

14. Merkel M, Eckel RH, Goldberg IJ: Lipoprotein lipase: genetics, lipid uptake, and regulation. J Lipid Res 2002, 43:1997-2006.
15. Bijvoet SM, Wiebusch H, Ma Y, Reymer PW, Bruin T, Bakker HD, Funke $H$, Assmann G, Hayden MR, Kastelein JJ: Compound heterozygosity for a known and a novel defect in the lipoprotein lipase gene (Asp250- > Asn; Ser2510- > Cys) resulting in lipoprotein lipase (LPL) deficiency. Neth $J$ Med 1996, 49:189-195.

16. Chan AO, But WM, Lau GT, Tse WY, Shek CC: A novel nonsense mutation in the LPL gene in a Chinese neonate with hypertriglyceridemia. Clin Chim Acta 2006, 368:120-124.

17. Al-Shali K, Wang J, Fellows F, Huff MW, Wolfe BM, Hegele RA: Successful pregnancy outcome in a patient with severe chylomicronemia due to compound heterozygosity for mutant lipoprotein lipase. Clin Biochem 2002, 35:125-130.

18. Rip J, Nierman MC, Ross CJ, Jukema JW, Hayden MR, Kastelein JJ, Stroes ES Kuivenhoven JA: Lipoprotein lipase S447X: a naturally occurring gain-offunction mutation. Arterioscler Thromb Vasc Biol 2006, 26:1236-1245.

19. Agirbasli M, Sumerkan MC, Eren F, Agirbasli D: The S447X variant of lipoprotein lipase gene is inversely associated with severity of coronary artery disease. Heart Vessels 2011, 26:457-463.

20. Gaudet D, Methot J, Kastelein J: Gene therapy for lipoprotein lipase deficiency. Curr Opin Lipidol 2012, 23:310-320.

\section{doi:10.1186/1476-511X-13-52}

Cite this article as: Chen et al:: A novel lipoprotein lipase gene missense mutation in Chinese patients with severe hypertriglyceridemia and pancreatitis. Lipids in Health and Disease 2014 13:52.

\section{Submit your next manuscript to BioMed Central and take full advantage of:}

- Convenient online submission

- Thorough peer review

- No space constraints or color figure charges

- Immediate publication on acceptance

- Inclusion in PubMed, CAS, Scopus and Google Scholar

- Research which is freely available for redistribution

Submit your manuscript at www.biomedcentral.com/submit
C) Biomed Central 